Provided for non-commercial research and education use. Not for reproduction, distribution or commercial use.

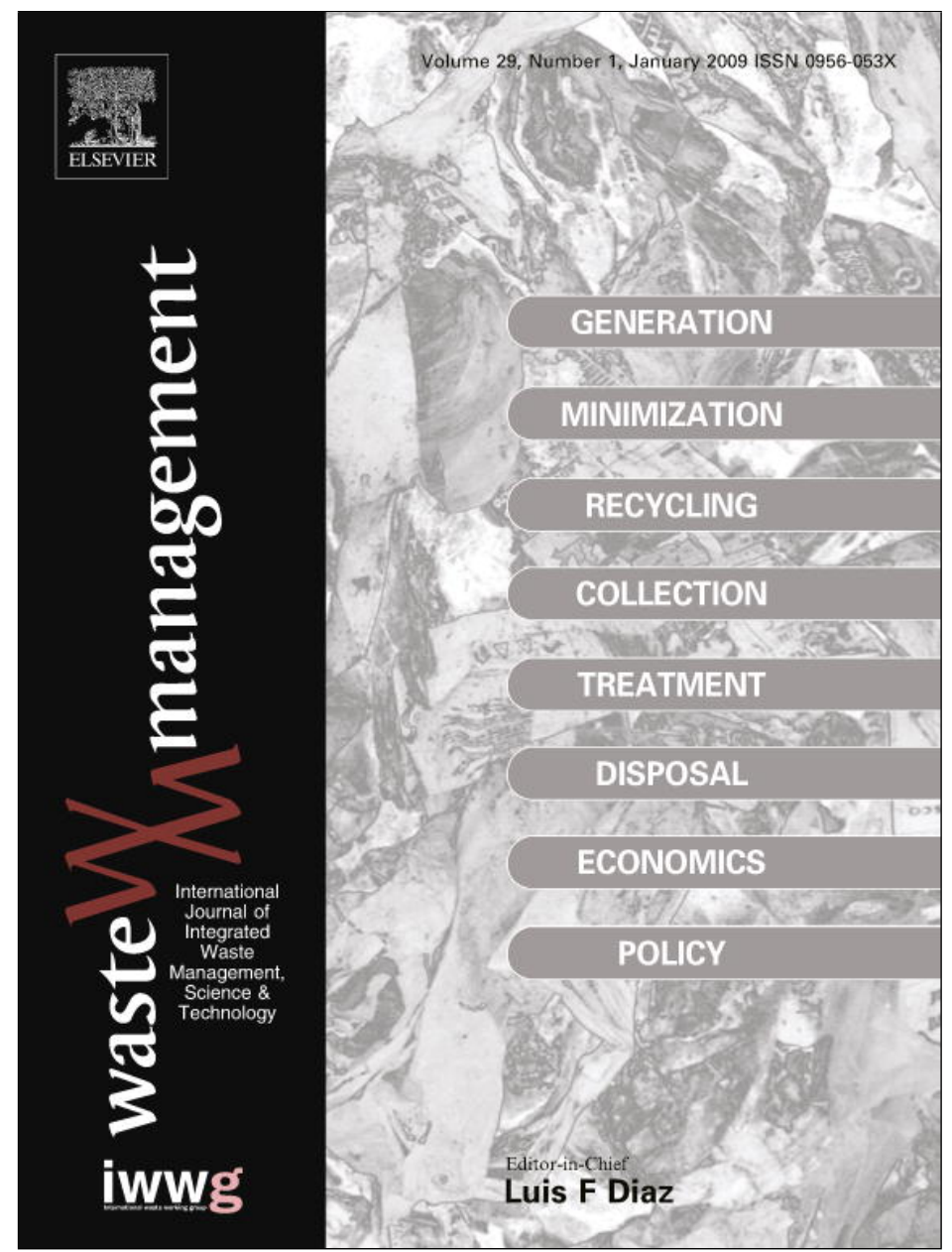

This article appeared in a journal published by Elsevier. The attached copy is furnished to the author for internal non-commercial research and education use, including for instruction at the authors institution and sharing with colleagues.

Other uses, including reproduction and distribution, or selling or licensing copies, or posting to personal, institutional or third party websites are prohibited.

In most cases authors are permitted to post their version of the article (e.g. in Word or Tex form) to their personal website or institutional repository. Authors requiring further information regarding Elsevier's archiving and manuscript policies are encouraged to visit:

http://www.elsevier.com/copyright 


\title{
Use of biosurfactants from urban wastes compost in textile dyeing and soil remediation
}

\author{
Enzo Montoneri ${ }^{\mathrm{a}, *}$, Vittorio Boffa ${ }^{\mathrm{a}}$, Piero Savarino ${ }^{\mathrm{a}}$, Fulvia Tambone ${ }^{\mathrm{b}}$, Fabrizio Adani ${ }^{\mathrm{b}}$, \\ Luca Micheletti $^{\mathrm{a}}$, Carlo Gianotti ${ }^{\mathrm{c}}$, Roberto Chiono ${ }^{\mathrm{c}}$ \\ a Dipartimento di Chimica Generale ed Organica Applicata, Università di Torino, Torino, Italy \\ ${ }^{\mathrm{b}}$ Dipartimento di Produzione Vegetale, Università di Milano, Milano, Italy \\ ${ }^{\mathrm{c}}$ Studio Chiono \& Associati srl, Rivarolo Canavese (TO), Italy
}

Accepted 31 January 2008

Available online 17 March 2008

\begin{abstract}
A compost isolated humic acid-like (cHAL) material was pointed out in previous work for its potential as auxiliary in chemical technology. Its potential is based on its relatively low $0.4 \mathrm{~g} \mathrm{~L}^{-1}$ critical micellar concentration (cmc) in water, which enables cHAL to enhance the water solubility of hydrophobic substances, like phenanthrene, when used at higher concentrations than $0.4 \mathrm{~g} \mathrm{~L}^{-1}$.

This material could be obtained from a 1:1 v/v mixture of municipal solid and lignocellulosic wastes composted for 15 days. The compost, containing $69.3 \%$ volatile solids, $39.6 \%$ total organic $\mathrm{C}$ and $21 \mathrm{C} / \mathrm{N}$ ratio, was extracted for $24 \mathrm{~h}$ at $65{ }^{\circ} \mathrm{C}$ under $\mathrm{N}_{2}$ with aqueous $0.1 \mathrm{~mol} \mathrm{~L}^{-1} \mathrm{NaOH}$ and $0.1 \mathrm{~mol} \mathrm{~L}^{-1} \mathrm{Na}_{4} \mathrm{P}_{2} \mathrm{O}_{7}$, and the solution was acidified to separate the precipitated cHAL in $12 \%$ yield from soluble carbohydrates and other humic and non-humic substances. In this work two typical applications of surfactants, i.e., textile dyeing (TD) and soil remediation by washing (SW), were chosen as grounds for testing the performance of the cHAL biosurfactant against the one of sodium dodecylsulfate (SDS), which is a well established commercial synthetic surfactant. The TD trials were carried out with nylon 6 microfiber and a water insoluble dye, while the SW tests were performed with two soils contaminated by polycyclic aromatic hydrocarbons $(\mathrm{PAH})$ for several decades. Performances were rated in the TD experiments based on the fabric colour intensity $(\Delta E)$ and uniformity $(\sigma \Delta E)$, and in the $\mathrm{SW}$ experiments based on the total hydrocarbons concentration $\left(\mathrm{CW}_{\mathrm{PAH}}\right)$ and on the residual surfactant $\left(C_{\mathrm{re}}\right)$ concentrations in the washing solution equilibrated with the contaminated soils. The results show that both cHAL and SDS exhibit enhanced performance when applied above their cmc values. However, while in the TD case a significant performance effect was observed at the surfactants cmc value, in the SW case the required surfactants concentration values were equivalent to $25-125 \times \mathrm{cmc}$ for $\mathrm{cHAL}$ and to $4-$ $22 \times \mathrm{cmc}$ for SDS. The vis-a-vis comparison of the two surfactants gave the following results: in the TD case the cHAL biosurfactant at $0.4 \mathrm{~g} \mathrm{~L}^{-1}$ yields good colour intensity and equal colour uniformity as SDS at $5 \mathrm{~g} \mathrm{~L}^{-1}$, in the SW case cHAL was found to enhance $\mathrm{CW}_{\text {PAH }}$ by a factor of 2-4 relative to SDS with one soil, whereas with the other soil the two surfactants behaved similarly. The $C_{\text {re }}$ data, however, showed that both soils absorbed by far more SDS (68-95\%) than cHAL (12-54\%). The results point out intriguing technological and environmental perspectives deriving from the use of compost isolated biosurfactants in the place of synthetic surfactants.

(C) 2008 Elsevier Ltd. All rights reserved.
\end{abstract}

\section{Introduction}

In previous work (Quagliotto et al., 2006) we have reported the isolation of a humic acid-like (cHAL) compound from food and green wastes compost. This

\footnotetext{
${ }^{*}$ Corresponding author. Tel.: +39011 6707597; fax: +390116707591.

E-mail address: enzo.montoneri@unito.it (E. Montoneri).
}

compound was found to have $1.10 \mathrm{meq}^{-1}$ of $\mathrm{COOH}$ functional groups and to exhibit very good surfactant properties: i.e., critical micelle concentration $(\mathrm{cmc})=0.403 \mathrm{~g} \mathrm{~L}^{-1}$ and surface tension at $\mathrm{cmc}\left(\gamma_{\mathrm{cmc}}=36.1 \mathrm{mN} \mathrm{m}^{-1}\right.$ in aqueous solution at $\mathrm{pH}$ 7. These data suggested that $\mathrm{cHAL}$ might perform as chemical auxiliary in many technological applications where synthetic surfactants are used. Indeed, cmc and $\gamma_{\mathrm{cmc}}$ values for cHAL are quite remarkable when compared with values for other commercial synthetic 
anionic surfactants (Rosen, 1989) such as sodium dodecylsulphate (SDS) with $\mathrm{cmc}=2.33 \mathrm{~g} \mathrm{~L}^{-1}$ and $\gamma_{\mathrm{cmc}}=39.5 \mathrm{mN}$ $\mathrm{m}^{-1}$. In addition to this, a phenanthrene (PHE) solubility study pointed out the capacity of cHAL to incorporate large hydrophobic molecules into its micellar core, with no change of its cmc value determined in the absence of other organic molecules (Quagliotto et al., 2006). As this interaction results in enhanced water solubility of hydrophobic molecules, the number of cases for technological application where this property might be exploited appeared to be numerous.

Choosing some case studies where the established SDS surfactants are used and comparing performances of cHAL and SDS in the same experimental conditions seemed to be the fairest way to assess the value of the newly proposed cHAL chemical auxiliary. We wish to report now some preliminary data on the comparative performances of the above two substances in textile dyeing (TD) by a water insoluble dye and in the surfactants assisted washing of soil (SW) contaminated by polycyclic aromatic hydrocarbons $(\mathrm{PAH})$. Both these case studies require the specific capacity of the two surfactants under comparison to enhance the water solubility of hydrophobic molecules. In the TD case, enhancement of the dye solubility in the aqueous dyeing bath is needed in order to achieve optimum colour intensity and uniformity in the dyed fabric. In the SW case, enhancement of PAH solubility in the soil washing solution allows better removal of the contaminants from the soil. In both cases, however, the con is represented by the environmental impact of the surfactant. In the TD case, the presence of the surfactant in the exhausted dyeing bath becomes an additional chemical to handle and may increase the cost of disposal of the exhausted bath. In the SW case, sorption of the surfactant and/or of the PAH-surfactant adduct by the soil may add one more contaminant (the surfactant) to the soil and/or lead to migration of PAH to the aquifers. These facts point out that the range of potential applications of surfactants may be very wide and that high tech specialized knowledge is required nowadays for each technological application. We wish therefore to stress that in this work we have chosen the TD and SW case studies not as problems to solve, but rather as grounds for assessing the value of the new cHAL biosurfactant relative to that of SDS.

\section{Experimental}

\subsection{Materials}

For the present work, cHAL was available from previous work (Quagliotto et al., 2006). This material had been isolated in $12 \%$ yield from a 15 -d aged food residues-green wastes compost by a $24 \mathrm{~h}$ extraction at $65^{\circ} \mathrm{C}$ under $\mathrm{N}_{2}$ with aqueous $0.1 \mathrm{~mol} \mathrm{~L}^{-1} \mathrm{NaOH}$ and $0.1 \mathrm{~mol} \mathrm{~L}^{-1} \mathrm{Na}_{4} \mathrm{P}_{2} \mathrm{O}_{7}$, followed by precipitation at $\mathrm{pH}<1.5$. It was characterized by the following data: $\mathrm{C}$ content $59.9 \mathrm{w} / \mathrm{w} \%$ in ash free dry matter, empirical formula $\mathrm{C}_{10} \mathrm{H}_{13.4} \mathrm{~N}_{0.86} \mathrm{O}_{3.4} \mathrm{~S}_{0.04}, \mathrm{pH}$ in water suspension 4.0, carboxylic groups $1.10 \mathrm{meq} \mathrm{g}^{-1}$, phenol groups $1.90 \mathrm{meq}^{-1}$, aliphatic C/aromatic $\mathrm{C}$ atom/ atom ratio 2.3 . The food residue and green waste mix before and after composting was characterized by the data reported in Table 1 . The effect of the microbial degradation occurring during 15-d composting is the decrease of the volatile solids and of the total organic $\mathrm{C}$ content relative to the ash and $\mathrm{N}$ content. There was no specific reason for choosing a 15-d aged compost as source of humic acid-like compounds. This work represents the start of a foregoing project funded by the Italian Regione Piemonte aiming primarily to upgrade biomass wastes in chemical technology. We are aware that composting may yield a wide range of different products depending on the compost waste mixtures and the composting time. For this reason we plan in the long term to isolate other humic-like substances from biomass wastes and to establish structureproperty relationships for such products. All other experimental details for the characterization of the compost and of cHAL, and for the isolation of cHAL have been reported previously (Quagliotto et al., 2006). Commercial SDS and all other reagents were purchased from Aldrich. Microfiber nylon 6 by Sniafibre (Italy) with the following specifications, i.e., filling dtex 88/72, warp dtex 167/30, and the disperse dye (Fig. 1) were available from previous work (Carpignano et al., 1985).

\subsection{Textile dyeing ( $T D)$}

Dyeing tests were carried out according to a previously reported procedure (Savarino et al., 2006) by using microfiber nylon 6 and the disperse dye 2 under the following conditions. The dye bath depth (i.e., the percentage of dye related to the fibre weight) was $7.1 \%$. Dyeing trials were performed in the absence and in the presence of either cHAL or SDS. In the latter case, the concentrations of the two surfactants were $0.40-1.20 \mathrm{~g} \mathrm{~L}^{-1}$ for cHAL and 1$5 \mathrm{~g} \mathrm{~L}^{-1}$ for SDS. Dye dispersion was helped by mechanical IKA Ultra Turrax T25 dispersion tool. The previously wetted fabric was introduced into the dye bath at $40^{\circ} \mathrm{C}$ and the temperature was raised to $80^{\circ} \mathrm{C}$ over 20 min and maintained for $1 \mathrm{~h}$. Other experimental conditions were liquidto-good ratio (LGR) 20 and $\mathrm{pH} 7$ maintained by $0.1 \mathrm{M}$ Tris buffer. The dyed fibre was then removed, rinsed,

Table 1

Moisture content $\left(\mathrm{MC}, \mathrm{g} \mathrm{kg}^{-1}\right)$, bulk density $\left(\mathrm{BD}, \mathrm{Mg} \mathrm{m}^{-3}\right), \mathrm{pH}$, volatile solids (VS, $\left.\mathrm{g} \mathrm{kg} \mathrm{dm}^{-1}\right)$, ash $\left(\mathrm{g} \mathrm{kg} \mathrm{dm}^{-1}\right)$, total organic C (TOC, $\left.\mathrm{g} \mathrm{kg} \mathrm{dm}^{-1}\right)$ and $\mathrm{N}\left(\mathrm{g} \mathrm{kg} \mathrm{dm}^{-1}\right)$ contents for compost mix before and after 15-d composting

\begin{tabular}{llllllll}
\hline & MC & BD & pH & VS & Ash & TOC & N \\
\hline Before composting & 558 & 0.55 & 6.3 & 747 & 253 & 439 \\
After composting & 628 & 0.64 & 7.8 & 693 & 307 & 396 & 14.1 \\
\hline
\end{tabular}




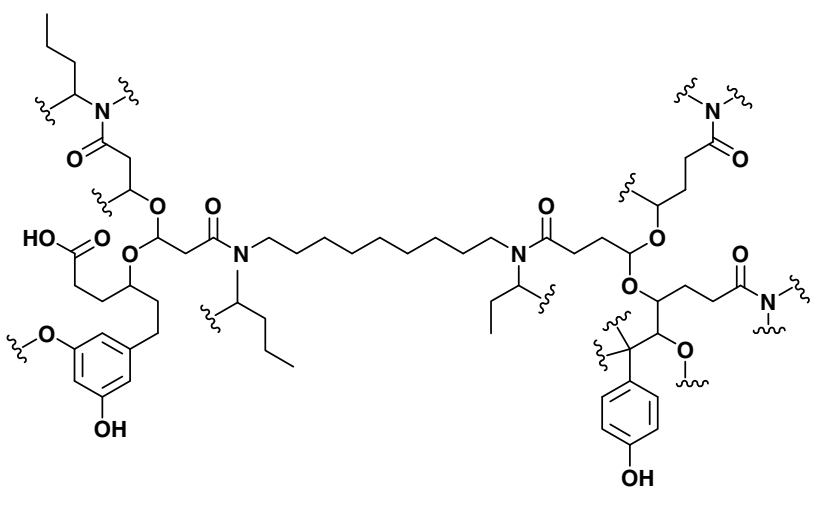

Fig. 1. Proposed molecular fragment for cHAL (Quagliotto et al., 2006). $\mathrm{H}$ bonded to $\mathrm{C}$ omitted; sinusoidal bold lines indicate other fragments $\mathrm{C}$, $\mathrm{O}$ and $\mathrm{N}$ atoms.

washed at $40^{\circ} \mathrm{C}$ with water solution containing soap $\left(2.5 \mathrm{~g} \mathrm{~L}^{-1}\right)$ and sodium carbonate $\left(2.5 \mathrm{~g} \mathrm{~L}^{-1}\right)$ at LGR 200 , rinsed again and dried at room temperature. The dyed product quality was evaluated by measurements of the fabric colour intensity $(\Delta E)$ and uniformity $(\sigma \Delta E)$ by tristimulous colorimetry. The $\Delta E$ indicator is the mean of nine determinations of the colour difference between the dyed and undyed fabric performed over nine different sites of the specimen, while $\sigma \Delta E$ is the standard deviation around the mean $\Delta E$ value. The results of the dyeing tests are reported in Table 2.

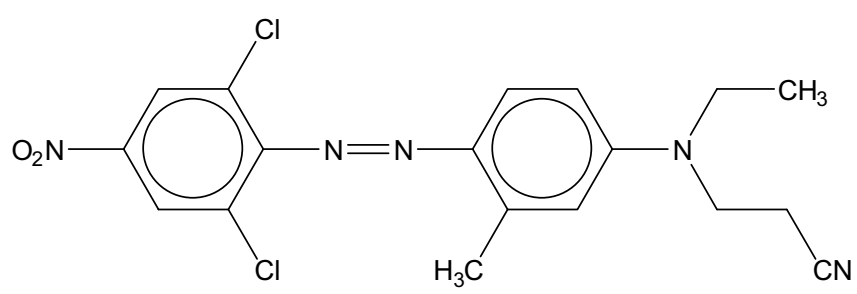

2

Table 2

Colour intensity $(\Delta E)$ and uniformity $(\sigma \Delta E)$ of nylon 6 microfiber dyed by the disperse dye 2 at $80^{\circ} \mathrm{C}, 1 \mathrm{~h}$ dyeing time and $20 \mathrm{~V} / \mathrm{w}$ liquor/good ratio in the absence of additives and in the presence of cHAL and SDS at variable additive concentration $\left(\mathrm{C}, \mathrm{g} \mathrm{L}^{-1}\right)$

\begin{tabular}{llll}
\hline Additive & $C$ & $\Delta E^{\mathrm{a}}$ & $\sigma \Delta E^{\mathrm{b}}$ \\
\hline None & 0.00 & $33.8 \mathrm{~A}$ & $1.31 \mathrm{c}, \mathrm{d}$ \\
SDS & 1.00 & $35.9 \mathrm{~B}$ & $1.85 \mathrm{~d}, \mathrm{e}$ \\
& 2.36 & $49.0 \mathrm{E}$ & $0.32 \mathrm{~b}$ \\
& 5.00 & $49.8 \mathrm{~F}$ & $0.21 \mathrm{a}, \mathrm{b}$ \\
cHAL & 0.40 & $46.5 \mathrm{D}$ & $0.28 \mathrm{a}, \mathrm{b}$ \\
& 0.80 & $45.8 \mathrm{C}$ & $0.80 \mathrm{c}, \mathrm{d}$ \\
& 1.20 & $45.9 \mathrm{C}$ & $0.59 \mathrm{~b}, \mathrm{c}$
\end{tabular}

${ }^{\mathrm{a}}$ Letters next to figures indicate $\Delta E$ inequalities by one-sided t-test at $95 \%$ confidence level (Natrella, 1966), i.e., $\mathrm{A}<\mathrm{B}<\mathrm{C}<\mathrm{D}<\mathrm{E}<\mathrm{F}$.

${ }^{\mathrm{b}}$ Letters next to figures indicate variance inequalities by $\mathrm{F}$ test at $95 \%$ confidence level (Natrella, 1966), i.e., $\mathrm{a}<\mathrm{b}<\mathrm{c}<\mathrm{d}<$ e.

\subsection{Soil washing $(S W)$}

Two soil samples (A, B) contaminated by polycyclic aromatic hydrocarbons $(\mathrm{PAH})$ were excavated at a depth of $9 \mathrm{~m}$ in a Northern Italian site where a coke production facility is located. Before analysis and/or extraction with the aqueous surfactants solutions, the soils were treated as follows. For each soil a $400 \mathrm{~g}$ lot was air dried at $60{ }^{\circ} \mathrm{C}$ for $24 \mathrm{~h}$ at constant weight. Afterwards, the soil lot was hand homogenized and $2.00 \mathrm{~mm}$ sieved. Each homogenized sample lot was then sampled for analytical purposes and for running the soil washing trials. The two soils were characterized by the data reported in Table 3. Soil texture (Faithfull, 2002), and pH, total organic $\mathrm{C}$ and $\mathrm{N}$ content, and cation exchange capacity was determined as previously reported (Adani et al., 2007). The total PAH soil content was determined by suspending the soil in a 1:1 acetone/hexane mixture at 1:10 solid/liquid ratio, sonicating and filtering and by GC analysis (Quagliotto et al., 2006) of the organic phase of the hydrocarbons listed in Table 4 . The total PAH concentration in the organic extract was calculated as the sum of the concentration values determined for each single hydrocarbon. This was then converted to total soil PAH concentration. The soil washing trials were performed similarly to a previously reported procedure (Deshpande et al., 1999). The soil sample taken from the homogenized lot was suspended in the surfactant washing solution at $1 / 10 \mathrm{~g} / \mathrm{mL}$ ratio and shaken for $24 \mathrm{~h}$ in a lab shaker at 150 cycles per min. After $2 \mathrm{~h}$ resting, the suspension was centrifuged and the collected liquid phase was analyzed for total $\mathrm{PAH}$ content by extraction with $\mathrm{CH}_{2} \mathrm{Cl}_{2}$ and $\mathrm{GC}$ analysis (as above) of the separated organic phase. The washing solutions were prepared by dissolving the proper amount of surfactant in water. The starting surfactants concentration in the washing solutions ranged from 1 to $50 \mathrm{~g} \mathrm{~L}^{-1}$. The cHAL solutions contained also variable amounts of a $0.16 \mathrm{M} \mathrm{Na} \mathrm{NPO}_{4}$ and $0.017 \mathrm{M}$ citric acid buffer in order to keep the humic acid in solution. Upon raising the surfactants concentration in the above range the solutions $\mathrm{pH}$ decreased from 7 to 6 in the cHAL solutions and from 6 to 5.6 in the SDS solutions. The residual surfactant concentration $\left(C_{\mathrm{re}}\right)$ in the soil washing solution recovered from the washing trial was determined by the solution organic $\mathrm{C}$ content which was compared with the

Table 3

Physicochemical parameters of soils used in this study. Standard deviations calculated from triplicates (Natrella, 1966)

\begin{tabular}{|c|c|c|}
\hline Parameter & Soil A & Soil B \\
\hline $\mathrm{pH}$ & $7.3 \pm 0.12$ & $7.5 \pm 0.08$ \\
\hline Total organic $\mathrm{C}, \mathrm{g} \mathrm{kg}^{-1}$ & $21.2 \pm 0.10$ & $29.4 \pm 0.80$ \\
\hline $\mathrm{N}, \mathrm{g} \mathrm{kg}^{-1}$ & $0.7 \pm 0.00$ & $0.8 \pm 0.00$ \\
\hline Cation exchange capacity, $\mathrm{cmol}^{+} \mathrm{kg}^{-1}$ & $4.0 \pm 1.02$ & $17.0 \pm 0.83$ \\
\hline Sand, w/w $\%$ & 57.9 & 61.9 \\
\hline Silt, w/w\% & 42.1 & 9.5 \\
\hline Clay, w/w $\%$ & 0 & 28.6 \\
\hline $\mathrm{PAH}, \mathrm{mg} \mathrm{kg}^{-1}$ & $271.9 \pm 32.9$ & $676.8 \pm 125.7$ \\
\hline
\end{tabular}


Table 4

Total $\mathrm{PAH}^{\mathrm{a}}\left(\mathrm{CW}_{\mathrm{PAH}}\right)$ and residual surfactant $\left(C_{\mathrm{re}}\right)$ concentrations after soil washing versus starting surfactant concentration $\left(C_{\mathrm{sr}}\right)$ in washing solution

\begin{tabular}{|c|c|c|c|c|c|c|c|}
\hline \multicolumn{2}{|l|}{ Surfactant } & \multicolumn{3}{|l|}{ cHAL } & \multicolumn{3}{|l|}{ SDS } \\
\hline$C_{\mathrm{sr}}, \mathrm{g} \mathrm{L}^{-1}$ & & 10 & 25 & 50 & 10 & 25 & 50 \\
\hline Soil A & $C_{\mathrm{re}}, \mathrm{g} \mathrm{L}^{-1}$ & 4.6 & 18 & 40 & 0.49 & 2.9 & 9.0 \\
\hline & $\mathrm{CW}_{\mathrm{PAH}}{ }^{\mathrm{b}}, \mathrm{mg} \mathrm{L}^{-1}$ & $0.44 \pm 0.018 \mathrm{e}$ & $0.53 \pm 0.010 \mathrm{f}$ & $0.67 \pm 0.011 \mathrm{~g}$ & $0.15 \pm 0.031 \mathrm{a}$ & $0.13 \pm 0.040 \mathrm{a}$ & $0.29 \pm 0.005 \mathrm{c}$ \\
\hline Soil B & $\begin{array}{l}C_{\mathrm{re}}, \mathrm{g} \mathrm{L}^{-1} \\
\mathrm{CW}_{\mathrm{PAH}}{ }^{\mathrm{b}}, \mathrm{mg} \mathrm{L}^{-1}\end{array}$ & $\begin{array}{l}7.2 \\
0.27 \pm 0.022 \mathrm{c}\end{array}$ & $\begin{array}{l}20 \\
0.33 \pm 0.008 \mathrm{~d}\end{array}$ & $0.34 \pm 0.040 \mathrm{~d}$ & $\begin{array}{l}0.16 \\
0.20 \pm 0.036 b\end{array}$ & $\begin{array}{l}4.1 \\
0.29 \pm 0.026 \mathrm{c}\end{array}$ & $\begin{array}{l}16 \\
0.38 \pm 0.027 \mathrm{~d}\end{array}$ \\
\hline
\end{tabular}

${ }^{a}$ Published (Sims and Overcash, 1983) water solubilities in $\mathrm{mg} \mathrm{L}^{-1}$ for the individual hydrocarbons found in this work are as follows: naphthalene 30 , acenaphthylene 3.93, acenaphthene 3.47, fluorene 1.98 , phenanthrene 1.29 , anthracene 0.07 , fluoranthene 0.26 , pyrene 0.14 , BaA benz[a] anthracene 0.014 , chrysene 0.002 , benzo[b]fluoranthene 0.0012 , benzo[k]fluoranthene 0.0006 , benzo[a]pyrene 0.0038 , indeno[1.2.3-c.d]pyrene 0.062 , dibenzo[a.h]anthracene 0.0005 , benzo[g.h.i]perylene 0.00026 .

b Average values and standard deviations from triplicate runs (see Section 2). Letters below figures indicate $\mathrm{CW}_{\mathrm{PAH}}$ average values inequalities by onesided t-test at 95\% confidence level (Natrella, 1966), i.e., $\mathrm{a}<\mathrm{b}<\mathrm{c}<\mathrm{d}<\mathrm{e}<\mathrm{f}<\mathrm{g}$.

organic $\mathrm{C}$ content of the starting surfactant solution. The organic $\mathrm{C}$ content of the washing solutions was determined as previously reported (Boyd et al., 1980). Soil washing trials were performed also with plain deionised water and with the plain buffer solution. For each soil sample, the washing trials were performed in triplicate at each surfactant concentration. Quantitative results in Table 4 are given as average values of triplicate runs with their standard deviations (Natrella, 1966). Standard deviations therefore encompass the total variability due to the degree of the starting soil lot homogeneity, to the sample manipulation and to the analytical procedure.

\section{Results}

\subsection{Performance of $c H A L$ and SDS in textile dyeing (TD)}

The results of dyeing nylon 6 microfiber with the disperse dye 2 in the presence and absence of cHAL and SDS are reported in Table 2. It may be observed that, as expected, the presence of the surfactants improves significantly the two product quality indicators, i.e., the colour intensity $(\Delta E)$ and the colour uniformity $(\sigma \Delta E)$ of the fibre. In the presence of SDS, compared with dyeing in the absence of surfactant $(C=0.00)$, the fibre $\Delta E$ appears to increase already at $1 \mathrm{~g} \mathrm{~L}^{-1}$ surfactant concentration. However, to be able to observe a significant improvement of $\sigma \Delta E$, the use of the additive at concentration equal to or above the surfactant cmc value $(C \geqslant 2.36)$ seems to be necessary. In the presence of cHAL, the improvement of both the fibre $\Delta E$ and $\sigma \Delta E$ is readily evident at the lowest investigated $C$ value $\left(0.40 \mathrm{~g} \mathrm{~L}^{-1}\right)$ which corresponds to the $\mathrm{cmc}$ value. Thus, it appears that with each additive a $\mathrm{g} \mathrm{L}^{-1}$ concentration value corresponding to the $\mathrm{cmc}$ value or above is needed to obtain improvement of the product colour intensity. The data, however, show that depending on the type of additive, the quality indicators respond in different ways to the increase of the additive concentration above its $\mathrm{cmc}$ value: i.e., in the presence of SDS at $C \geqslant 2.36 \mathrm{~g} \mathrm{~L}^{-1}$, both the colour intensity and the colour uniformity of the fibre improve significantly upon increasing the additive concentration; in the presence of cHAL at $C \geqslant 0.40 \mathrm{~g} \mathrm{~L}^{-1}$, both the colour intensity and the colour uniformity of the fibre become significantly worse upon increasing the additive concentration.

\subsection{Performance of $c H A L$ and SDS in soil washing ( $S W)$}

For the two investigated soils contaminated by $\mathrm{PAH}$, the results of their physicochemical characterization and of the washing trials performed in the absence and in the presence of cHAL and SDS are reported in Tables 3 and 4 , respectively. Table 3 shows that the two investigated soils are significantly different, particularly their texture, total organic $\mathrm{C}$, cation exchange capacity and $\mathrm{PAH}$ contamination level. In the washing trials of these soils we have found that the total $\mathrm{PAH}$ concentrations $\left(\mathrm{CW}_{\mathrm{PAH}}\right)$ in pure water or in the blank buffer aqueous solution, at completion of the washing trials, were $0.030 \pm 0.032 \mathrm{mg} \mathrm{L}^{-1}$ for soil $\mathrm{A}$ and $0.052 \pm 0.006 \mathrm{mg} \mathrm{L}^{-1}$ for soil $\mathrm{B}$. These values are not significant (for soil A) or below the water solubility values (for soil $\mathrm{B}$ ) for most of the found single hydrocarbons (Table 4). The $\mathrm{CW}_{\mathrm{PAH}}$ values in the washing solutions of both surfactants at $1 \mathrm{~g} \mathrm{~L}^{-1}$ were not significantly different from those in pure washing water and therefore are not reported. Significant enhancement of $\mathrm{CW}_{\mathrm{PAH}}$ (by one order of magnitude) was found using surfactant solutions at $10-50 \mathrm{~g} \mathrm{~L}^{-1}$ starting concentration as shown in Table 4. These surfactants concentration values are well above the cmc values for both surfactants, being equivalent to $25-125 \times \mathrm{cmc}$ for $\mathrm{cHAL}$ and to $4-22 \times \mathrm{cmc}$ for SDS. The data show that cHAL, compared with SDS at the same starting surfactant concentration, performs equally (in soil B) or $3 \times$ better (in soil A). Table 4 also shows that heavy surfactant depletion occurs for the washing solutions at completion of each washing trial. A fall in concentration of the surfactants in the washing solutions appeared consistent right after mixing the soil sample and the surfactant solution, and lasted until the end of the washing trials. The fast rate of surfactant loss from the solution suggests sorption by the soil more than biodegradation of the surfactant. This phenomenon occurs in greater extent for the SDS than for the cHAL washing solutions: i.e., the percentage surfactant loss after washing relative to the starting 
solution was $68-95 \%$ for SDS and $12-54 \%$ for cHAL. Consistently with this fact, a strong $\mathrm{pH}$ change from the initial values of 5.6-6 to 8.1-8.2 was found in the recovered SDS solutions. Notwithstanding the strong surfactants sorption of the soil, both cHAL and SDS residual concentrations were still above the cmc values of the two surfactants, except for the case of the $10 \mathrm{~g} \mathrm{~L}^{-1}$ starting SDS solutions.

\section{Discussion}

The two applications we have chosen as grounds for testing the performance of the cHAL biosurfactant against the one of sodium dodecylsulfate (SDS) are quite challenging for many reasons.

Fabric dyeing is rated based on the product quality, the process cost and on the environmental impact caused by the disposal of the exhausted dyeing bath (Lorimer et al., 2001; Mohan et al., 2002). These process indicators depend on three main parameters, such as the liquor-to-good V/w ratio (LGR), and the type and concentration of the dye and of the additive in the dyeing bath. To compare performance of cHAL and SDS in textile dyeing, we chose a particularly challenging dye system, i.e., microfiber nylon 6 and the water insoluble dye 2. Compared with conventional fibres, the chosen microfiber nylon 6 (see Section 2.1 ) is an ultra-fine fibre which shows more surface area for the interaction with dyes. On the other hand, dyeing with the water insoluble dye 2 requires more and more dye solubility in the bath since poor water solubility of the dye causes non-homogenous distribution of the dye throughout the fabric solid phase and the accumulation of the dye preferably on the fibre surfaces. This fact causes less uniform dyeing and an increased demand of colorant to give comparable colour yield. The role of surfactants in such system is based on their capacity to micellize and to increase the dye water solubility by incorporating it into the micellar hydrophobic core. Under these circumstances, while the use of synthetic commercial surfactants is well established, the use of a humic-like biosurfactant in dyeing technology is rather new. Indeed, the interaction of peat humic acids with some water insoluble dyes has already been reported (Vashurina et al., 2003), but its effect on dye performance during technological application has never been reported.

In our dyeing tests, the additives $\mathrm{g} \mathrm{L}^{-1}$ concentration values were chosen to include the reported $\mathrm{cmc}$ values of each surfactant (see Section 1). With both surfactants a $\mathrm{g} \mathrm{L}^{-1}$ concentration value corresponding to the $\mathrm{cmc}$ value or above (Table 2) is required to obtain improvement of the product colour intensity, which appears consistent with the enhancement of the dye water solubility through incorporation into the surfactant micellar core. The best colour uniformity attained in our experimental plan corresponds to $0.21 \leqslant \sigma \Delta E \leqslant 0.28$ (Table 2). Based on $\mathrm{F}$ test at $95 \%$ confidence level, $\sigma \Delta E$ values in this range are not statistically different from one another. These values are attained in the presence of SDS at $5 \mathrm{~g} \mathrm{~L}^{-1}$ or in the presence of cHAL at $0.4 \mathrm{~g} \mathrm{~L}^{-1}$. Under these conditions, the colour intensity in the presence of SDS was 49.82 , whereas in the presence of cHAL it was slightly lower ( $\Delta E 46.46)$. Specifically for cHAL, it is interesting to observe that both the colour intensity and the colour uniformity seem to decrease upon increasing the cHAL concentration above its $\mathrm{cmc}$ value. This may indicate that, in the presence of the biosurfactant at the higher micelle concentrations, the dye is too strongly held into the biosurfactant micellar core and less available to interact with the fibre. In a second experiment we chose to compare cHAL and SDS in the extraction of technological soil contaminants by washing with aqueous solutions, which involves quite a complex process. Surfactants are added to water to increase the hydrophobic contaminants water solubility and thus to enhance the extraction efficiency of the soil washing solution. Large differences in contaminants recoveries are reported in literature for similar hydrocarbons and surfactants in different soils since many factors depend on the soil nature (Janzen et al., 1996; Mulligan et al., 2001) and on the couple contaminant-surfactant. Moreover contaminant-soil and soilsurfactants interactions (Pennell et al., 1993; Chlou et al., 1986) are also involved. For these reasons, recoveries of hydrocarbons from contaminated soils may be much lower than expected based on measured hydrocarbons water solubility in the aqueous surfactant solution. In this paper the hydrocarbon recovery from the soils was not an important issue, the main purpose of the work being the assessment of the performance of the cHAL biosurfactant relative to that of the commercial SDS surfactant.

The soils investigated in this work had been exposed to polycyclic aromatic hydrocarbons (PAH) contamination for several decades. For our purpose, the two soils were chosen for their different physicochemical parameters (Table 3), which might influence in a different way the performances of the two surfactants. With these soils, the surfactant effect on the soil washing process efficiency was observed (Table 4) at starting surfactant concentrations $\left(10-50 \mathrm{~g} \mathrm{~L}^{-1}\right)$, which are equivalent to $25-125 \times \mathrm{cmc}$ for cHAL and to $4-22 \times \mathrm{cmc}$ for SDS. Therefore, compared with the textile dyeing case, in the soil washing trials the required additive concentration, which allowed observation of a significant effect thanks to the additive, was 4 20 times higher.

The relatively high surfactant concentration required in soil washing points out that this technology is even more demanding for surfactants than textile dyeing. Indeed, one matter of concern in soil washing is the surfactant sorption of the soil. This may imply both higher process cost and/or environmental impact, depending on the sorbed surfactant. In our case, the organic $\mathrm{C}$ analyses of the surfactants solution after the washing trials indicated a strong depletion of surfactants from the washing solution at the end of the washing trials, as shown by the vis-à-vis comparison of the starting and residual surfactant concentrations in Table 4. The data show that the surfactant 
depletion occurred to a greater extent for the SDS than for the cHAL washing solutions. It is readily evident that there is a significant material exchange between soils $\mathrm{A}$ and $\mathrm{B}$ and the surfactants solutions, i.e., the soils absorb consistent amounts of surfactants from the washing solutions and release $\mathrm{PAH}$ into these solutions. The data evidence a clear effect of the soil matrix on PAH desorption by both surfactants. Notwithstanding the surfactants sorption of the soils, cHAL is shown to enhance PAH desorption from the soil by a $10 \times$ factor relative to water and by a $3 \times$ factor relative to SDS. A main factor causing the lower performance of SDS may be its much higher rate of sorption by the soils. This is a further argument in favor of cHAL, both from the soil washing process cost and from the surfactant environmental impact viewpoints (Feitkenhauer and Meyer, 2002; Luth et al., 1996).

We are aware that results of this work are not exhaustive and pose a number of specific questions for each of the investigated applications. Our experimental design is not so powerful to allow isolation of the effects of the independent variables connected with each of the investigated systems. However, we feel that the main purpose of this work is fulfilled. The data show a rather competitive performance of cHAL relative to SDS both in the textile dyeing trials and in the soil washing trials. Our experimental results do not include data on the environmental impact of the surfactants. However, it should be considered that while the environmental toxicity of synthetic alkylsulfates is assessed (Feitkenhauer and Meyer, 2002), composts (Luth et al., 1996) and humic acids (Vashurina et al., 2003), by virtue of their structural similarity with soil natural organic matter, have been shown to be environmentally friendly materials. These considerations allow us to expect that the compost biosurfactant may be used as well as or more conveniently than SDS as chemical auxiliary in other technological applications. As to the main issue of compost matter being a potential source of chemical auxiliaries, we wish to point out that our cHAL was isolated from a mixture of food residues and public park green wastes which had been previously composted for 15-d (Quagliotto et al., 2006). Composting, however, yields a wide range of different products depending on the starting waste mixtures and on the product maturity. It is quite likely that by tuning up the compost process one could obtain other humic-like surfactant matter showing improved performance, which could be tailored for specific applications and cases. These facts, coupled with the expected environmental friendly impact of the above biosurfactants (Luth et al., 1996; Vashurina et al., 2003), with their potential monetary value (Modler et al., 2006; Houston \& Associates, Inc., 2007) and with the large use of surfactants in modern life, allow us to expect well promising economic benefits from the exploitation of compost as a source of chemical auxiliaries to recycle to the chemical industry. There is no doubt, however, that optimization of the process for the extraction of humic-like substances must go along with the product development. Among all available biomass wastes, compost is the richest source of organic matter. It is found in confined spaces and may have relatively low water (35-55\%) and high organic matter (26$50 \%$ ) contents (Quagliotto et al., 2006; Ozores-Hampton and Obreza, 2007). It seems therefore a very promising waste material candidate, which will allow the development of an industrially feasible process for the extraction of biosurfactants. We are confident that the procedure reported in the experimental section for the isolation of humic acid-like compounds may be optimized. In addition to this, it is not known at this point whether the selective isolation of the humic acid-like compounds is necessary in all the cases. Raw compost extracts containing fulvic acids and other active organic substances together with humic acidlike compounds might show just as good or better surfactant properties for specific needs. In this case, the needed surfactant mix might be extracted with an even simpler procedure than the one used in this work. We feel, in conclusion, that the results of this work certainly point out a new renewable source of surfactants and stimulate further intriguing work with other composts to exploit their full potential.

\section{Acknowledgment}

This work has been carried out using Regione Piemonte (I) funds within Cod. C 13 Sustainable Development project.

\section{References}

Adani, F., Genevini, P.L., Ricca, G., Tambone, F., Montoneri, E., 2007. Soil humic acids modification after four years of compost application. Waste Manage. 27, 319-324.

Boyd, S.A., Sommers, L.E., Nelson, W., 1980. Change in the humic acid fraction of soil resulting from sludge application. Soil Sci. Soc. Am. J. 44, 1179-1186.

Carpignano, R., Savarino, P., Barni, E., Di Modica, G., Papa, S.S., 1985. Developments in the application of quantitative structure-property relationships of dyes. J. Soc. Dyers Colour. 101, 270-276.

Chlou, C.T., Malcolm, R.L., Brinton, T.I., Kile, D.E., 1986. Water solubility enhancement of some organic pollutants and pesticides by dissolved humic and fulvic acids. Environ. Sci. Technol. 20 (5), 502508.

Deshpande, S., Shiau, B.J., Wade, D., Sabatini, D.A., Harwell, J.H., 1999. Surfactant selection for enhancing ex situ soil washing. Water Res. 33, $351-360$

Faithfull, N.T., 2002. Methods in Agricultural Chemical Analysis: A Practical Handbook. CABI Publishing, NY.

Feitkenhauer, H., Meyer, U., 2002. Anaerobic digestion of alcohol sulfate (anionic surfactant) rich wastewater - batch experiments. Part II: influence of the hydrophobic chain length. Bioresour. Technol. 82, $123-129$.

Houston, C. A. \& Associates, Inc., 2007. Opportunities in Performance Surfactants in West Europe. <www.colin-houston.com>

Janzen, R.A., Xing, B., Gomez, C.C., Salloum, M.J., Drijber, R.A., Mcgill, W.B., 1996. Compost extract enhances desorption of anaphthol and naphthalene from pristine and contaminated soils. Soil Biol. Biochem. 28, 1089-1098.

Lorimer, J.P., Mason, T.J., Plattes, M., Phull, S.S., Walton, D.J., 2001. Degradation of dye effluent. Pure Appl. Chem. 73, 1957-1968. 
Luth, H.K., Heerenklage, J.C., Stegmann, R., 1996. Enhancement of the biological degradation of soils contaminated with oil by the addition of compost. Acta Biotechnol. 16, 19-30.

Modler, R.F., Willhalm, R., Yoshida, Y., 2006. Ceh Marketing Research Report. Linear Alkylate Sulfonates. <http://www.sriconsulting.com/ CEH/Public/Reports/Sample.pdf $>$.

Mohan, S.V., Rao, N.C., Prasad, K.K., Karthikeyan, J., 2002. Treatment of simulated reactive yellow 22 (azo) dye effluents using Spirogyra species. Waste Manage. 22, 575-582.

Mulligan, C.N., Yong, R.N., Gibbs, B.F., 2001. Surfactant-enhanced remediation of contaminated soil: a review. Eng. Geol. 60, 371-380.

Natrella, M.G., 1966. Experimental statistics. In: Besson, F.S., Astin, A.V. (Eds.), National Bureau of Standards Handbook 91. US Government Printing Office, Washington, DC.

Pennell, K.D., Abriola, L.M., Weber Jr, W.J., 1993. Surfactant-enhanced solubilization of residual dodecane in soil columns.1. Experimental investigation. Environ. Sci. Technol. 27, 2332-2340.
Ozores-Hampton, M., Obreza, T., 2007. Beneficial uses of compost in Florida vegetables crops, Compost facilities in Florida.pdf. <www. imok.ufl.edu/compost/pdf/Compost_Utilization.pdf $>$. [accessed April 13, 2007].

Quagliotto, P.L., Montoneri, E., Tambone, F., Adani, F., Gobetto, R., Viscardi, G., 2006. Chemicals from wastes: compost-derived humic acid-like matter as surfactant. Environ. Sci. Technol. 40, 1686-1692.

Rosen, M.J., 1989. Surfactants and Interfacial Phenomena, 2nd ed. Wiley, NY.

Savarino, P., Buscaino, R., Piccinini, P., Barolo, C., Montoneri, E., 2006. Effects of additives on the dyeing of polyamide fibers. Part II: methyl$\beta$-cyclodextrin. Dyes Pigments 69, 7-12.

Sims, R.C., Overcash, M.R., 1983. Fate of polynuclear aromatic compounds (PNAs) in soil-plant systems. Residue Rev. 88, 1-68.

Vashurina, Yu.S., Pogorelova, A.S., Kalinnilkov, Yu.A., 2003. Effect of humic acids on the state of disperse, acid, and vat dyes in aqueous solutions. Russ. J. Appl. Chem. 76, 1489-1493. 